\title{
Using sentiment analysis to measure emotional toxicity of social media data during the COVID pandemic
}

\author{
Loreen M. Powell, Bloomsburg University of Pennsylvania, lpowell@bloomu.edu \\ Carl M. Rebman, Jr., University of San Diego, carlr@sandiego.edu \\ Anna Dempsey, Bloomsburg University of Pennsylvania, amd91677@huskies.bloomu.edu \\ Cori J. Myers, Lock Haven University,CMyers@lockhaven.edu
}

\begin{abstract}
The current health pandemic has altered the world's emotional state via imposed social distancing restrictions, quarantines, illness, anxiety, depression, death, layoffs, and organization closures. The pandemic has prompted a societal change which accelerated the digital transformation of communication and social media usage for customers and organizations. This study's purpose endeavors to conduct a qualitative analysis of the subjective nature and changes in toxicity of social media posts, before and during COVID-19. The research methodology uses Microsoft Azure Learning and Microsoft Excel Add-In to conduct a sentiment analysis of one company's social media posts and compare end-users' emotional state and toxicity of comments, before and during the pandemic. The results may assist companies with additional tools to understand the subjective nature of social media posts and improve business decision making. Educators and researchers may apply this technique to other business functions and challenges.
\end{abstract}

Keywords: sentiment analysis, social media data, COVID decision making, Azure machine learning

\section{Introduction}

On January 20, 2020, the United States (US) reported its first Coronavirus (COVID-19) case (Wikipedia, 2021). On February 6, 2021, Patricia Bowd, a 57-year-old Northern California female became the first reported, COVID-19-related fatality (Moon, 2020). As days and months progressed, the pandemic spread across the nation vastly infecting thousands of people and deaths rose. A pandemic has been defined as an epidemic (the extremely fast spread of a particular highly infectious disease to a populace in a short time) that crosses international boundaries (Jones \& Keynes, 2020). COVID-19 caused much concern as its behavior and impact greatly resembled that of a previous 1918 deadly influenza pandemic. That influenza, also known as the Spanish flu, infected approximately 500 million people around the world and resulted in the deaths of 50 to 100 million people worldwide ( $3 \%$ to $5 \%$ of the world population), distinguishing it as one of the deadliest pandemics in human history (Jilani et al., 2020).

On March 11, 2020, the World Health Organization began announcing global health recommendations to decrease morbidity and mortality (Moukarzel et al., 2020). Days later, on March $13^{\text {th }}, 2020$, COVID-19 was declared a national emergency (Gostin et al., 2020). This action would lead to all states in the US being placed under a quarantine. The quarantine closed indoor dining, shut down nonessential businesses, forced businesses to work remotely, and permitted only vital travel. As part of the quarantine, the Centers for Disease Control and Prevention (CDC) created many different procedures for the public to follow. 


\section{Issues in Information Systems}

Volume 22, Issue 1, pp. 200-214, 2021

Most prominently, the CDC advocated for "Social Distancing, which is keeping a safe space (at least six feet) between yourself and other people who are not from your household" (National Center for Immunization and Respiratory Diseases (NCIRD), Division of Viral Diseases, 2020a).

Social distancing and isolation requirements caused major increases in social media use (Barnes \& Willis, 2020). A recent national study by Kantar Groups and Affiliates (2020) surveyed over 25,000 consumers within 30 different markets regarding the consumers' social media usage, attitudes, habits, and expectations during the global health crisis. They found increased usage across all social media messaging platforms for consumers 18-34 years of age. Furthermore, it was reported that common social media usage for applications like WhatsApp, Facebook, and Instagram increased over $40 \%$ for consumers under 35 years of age. Thus, many people under 35 use social media to communicate with friends, family, work, school, and organizations. They also created six consumer segments (see Figure 1) which illustrate different emotions that were used in the sentiment analysis (Kantar, 2020).

\section{The six Kantar Coronavirus Consumer Segments}

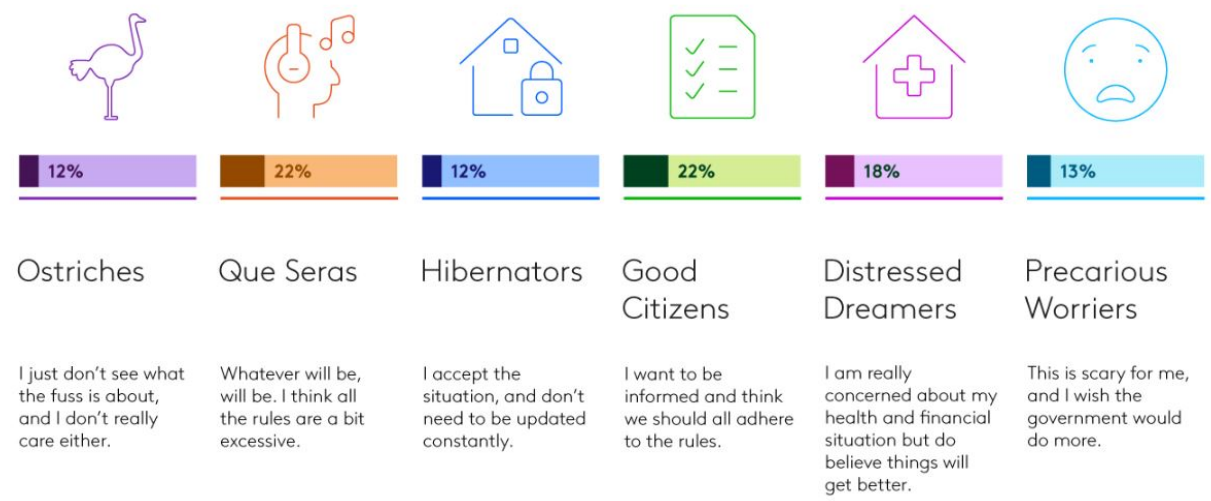

Figure 1. Six Kantor Coronavirus Consumer Segments

To harness the qualitative data online, researchers and organizations can perform a sentiment analysis to assess the overall tenor of the comments. Sentiment analysis is "the process of computationally categorizing opinions expressed in a piece of text to determine whether the writer's attitude towards a particular topic, product, etc. is positive, negative or neutral" (Dictonary.com, 2018, p. 1). The most common uses of sentiment analysis include the analysis of public opinion, Twitter, Facebook, market research, and social sciences. The sentiment analysis can help companies determine changes in public opinion regarding their products or company (Tennakoon, 2020). This tool can be helpful considering that social media has become a popular tool for developing and participating in civic discourse (Bandeli et al., 2018).

The goal of this study was to examine the subjective nature and emotional toxicity of COVID-19 data via a sentiment analysis of an organization's social media comments, before and throughout COVID-19. This paper seeks to expand upon previous literature, to provide a demonstration of sentiment analysis using Azure Machine Learning with Excel and to assist organizations considering using social media data for business decisions. The rest of this paper is as follows. First, relevant literature is discussed followed by the research methodology. The manuscript concludes with results, limitations, and future research. 


\section{Review of literature}

The onset and rapid spread of COVID-19 has influenced the human mindset and individual actions worldwide. Factors like anxiety, fear, depression, and grief evolved from being isolated to job loss to death of loved ones and drove people to engage more with social media and other potentially destructive behaviors like drug and alcohol abuse. DeValck (2021) explains that people often turn to social media during a crisis as a community resource or for emotional support. She posits that social media aids users in understanding what is happening through entertaining videos or practical information to seek support. Never has there been so much data publicly available online. While some data proves helpful and insightful, other social media posts exude toxic, harassing, and discriminatory opinions (Leetaru, 2018). Even before COVID-19, articles about social media becoming too toxic peppered the news as politicians, academicians, and celebrities alike broadcasted rants on Twitter and Facebook (Leetaru, 2018). As COVID-19 advanced, Kashif and Rehman (2020) documented the rise in social media and found that, in a study of 1092 people, $48 \%$ of respondents reported becoming addicted to social media during the pandemic. As the population increasingly took to social media, toxicity increased especially on politically charged topics including COVID-19 (Majo-Vasquez et al., 2020). In the last year, the increase in the toxic nature of social media posts may relate to negative influences of COVID-19 on the emotional state of the general population and special groups (e.g., young adults, parents and children, communities of color, essential workers) and the increase in well-documented behaviors like drug and alcohol abuse that can alter one's mindset and lead to uninhibited actions.

\section{Emotional States of an End-User During a Pandemic}

While social distancing was enforced to flatten the curve and stop COVID's spread, negative consequences have surfaced from these isolating measures. Individuals were classified as essential and non-essential employees. Non-essentials were forced to stay at home and work there, thus isolating them from society. If social distancing guidelines were followed diligently, the only human contact for much of the population would be at a store given the designation by the government as essential, or while social distancing outside one's house or street, or using electronic communications such as cell phones, FaceTime, or Zoom. In some cases, during the first peak of the pandemic, many cities and towns were prohibiting meeting in any gatherings even if socially distanced. Leung et al.'s (2018) epidemic mathematical model predicted the occurrence of school closures that reduced or eliminated social contact between children in school classes and replaced by social contacts outside of school.

The stay-at-home orders also created an increase in isolation when compared to pre-COVID-19 (Novotenty, 2019). Other reports and studies on self-isolation conducted in countries such as Italy and UK found that isolation effectively mitigated the spread of the virus but precipitated increases in psychological issues and other medicals (Bullman, 2020; Pietromarchi, 2020; Jones \& Keynes, 2020). Studies observed that elderly groups were particularly affected as they experienced loneliness and isolation due to separation from relatives and loss of social interactions (Shaw, 2020, Robinson, 2019). The withdrawal from activities and loss of social support has been found to cause isolated and lonely elderly people have less immunity and are more susceptible to inflammation and infections (Novotney, 2019). Of great concern, loneliness and isolation resulted in an increase in suicides in elderly males (Singer, 2018). As a result, many national programs were launched in Australia, Denmark, and the United Kingdom to raise awareness for loneliness, address social isolation, and raise awareness about alcoholism and depression.

The pandemic also gave rise to grief caused by loss of a loved one, job, finances, and support (National Center for Immunization and Respiratory Diseases (NCIRD), Division of Viral Diseases, 2020b). 


\section{Issues in Information Systems}

Volume 22, Issue 1, pp. 200-214, 2021

Emotions like grief normally follow losing a loved one or going through a traumatic event. Many times, grief instigates contradicting feelings and emotions causing confusion. In some cases, grief may cause denial. While confronting grief and seeking support serve as optimal coping mechanisms, the imposed isolation during the pandemic created barriers to accessing assistive services. Consequently, those suffering in silence can endure long-term, detrimental complications to one's health (Alexander, 2020).

Isolation, grief, and anxiety arising from the pandemic and its effects resulted in an increase in alcohol sales and consumption. This did not come as much of a surprise given that data from previous pandemics illustrated an increase of substance abuse during disasters (Rodriquez et al., 2021). Consequently, increased use of alcohol can cause negative changes in emotional states (e.g., depression). Many studies and reports have been conducted investigating how increased consumption can impact people and society (Kilgore et al., 2021; Szajnoga et al., 2021; McKetta et al., 2021, Chodkiewicz et al., 2021; Pollard et al., 2021; Neill et al., 2021).

Figure 2 shows the increase of alcohol sales in terms of weekly impact during the first wave of COVID19 (Drizly, 2020). Clearly, staying at home did not deter purchasing alcohol, as e-commerce alcohol sales rose from 2010 to 2020. In fact, Figure 3 illustrates the impact of COVID-19 as the first three months had accounted for almost the previous 10 years of sales combined.

\section{Weekly Sales Impact}

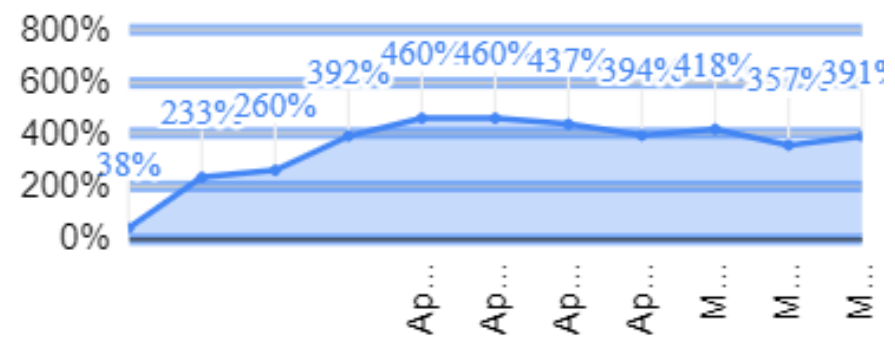

Figure 1. Weekly alcohol sales first wave of COVID-19 (Drizly, 2020)

\section{Then this happened.}

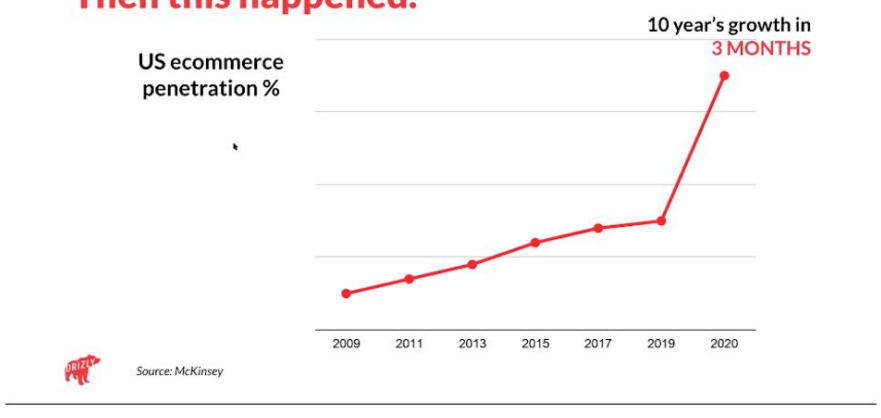

Figure 2. Alcohol E-Commerce Sales 2010-2020 (FORBES)

The reports and studies also investigated the reasons that alcohol increased during COVID-19. Some of the main reasons include stress and anxiety due to lockdown and stay-at-home orders, job loss, disrupted schedules/routines, boredom, loneliness, and for some, just the increase of cooking and drinking with dinner free of the worry about drinking and driving. Figure 4 from Statista provides an illustration of the 


\section{Issues in Information Systems}

Volume 22, Issue 1, pp. 200-214, 2021

type and strength of the different factors. While the data is taken from Canadian respondents, the factors can be generalized to other countries such as the US.

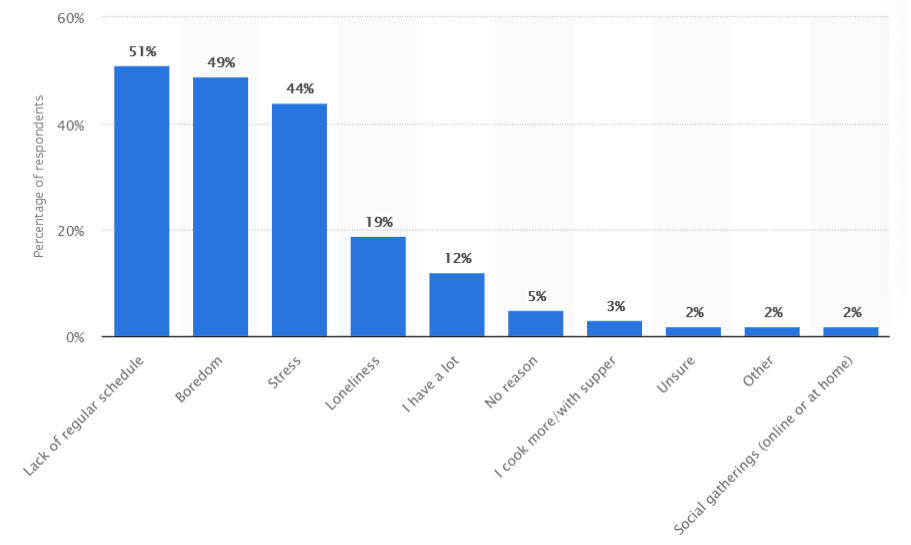

Figure 3. Reasons for Increase in Alcohol Consumption in Canadians

The studies also revealed some other interesting insights. For example, Alcohol.org (2021) found that drinking at home increased significantly during COVID-19, and more specifically, on-the-job drinking. The website's interactive infographic (see https://www.alcohol.org/guides/work-from-home-drinking/) shows the percentage of drinkers in each state working from home. Figure 5 depicts the heaviest drinking US states; the top two were Texas and California (Gates, 2020).

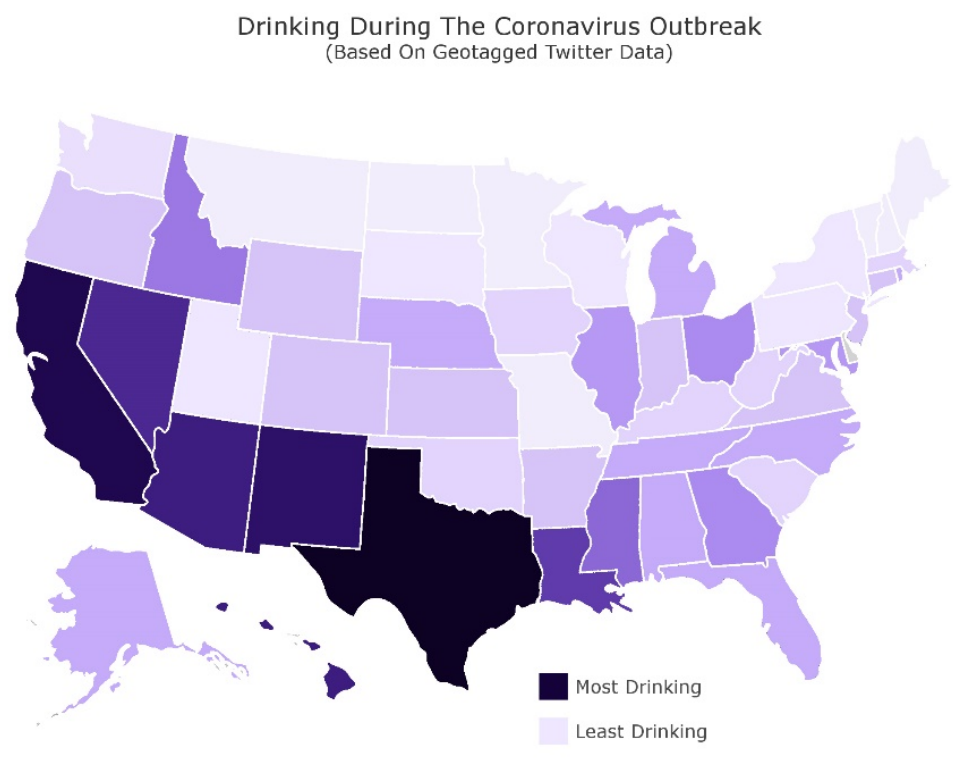

Figure 5. Heaviest Volume of COVID-19 Drinking per State

Drinkaware (2021) studied the correlation between alcohol and depression. They found that feelings of depression, characterized as episodes of sadness, lethargy, and loss of interest in life among others, can be brought on after heavy drinking. These states may disrupt normal daily activity, careers, hobbies, and relationships (Ratini, 2020). While the Drinkaware research has shown that reducing drinking can improve mood, a strong correlation exists between heavy drinking and suicidal thoughts, attempts, and 


\section{Issues in Information Systems}

Volume 22, Issue 1, pp. 200-214, 2021

deaths. Moreover, alcohol has been known to cause loss of inhibitions and impulsive behavior resulting in decisions that people may not otherwise make. Furthermore, since alcohol is a depressant, it may have a greater impact on brain function.

Clearly, a circular relationship exists whereby factors like anxiety, stress, loss, grief, and depression may push greater alcohol consumption, and consequently, alcohol consumption can intensify negative emotions like anxiety and depression, among others. During COVID-19, heightened emotional states, increased alcohol consumption which can induce or deepen these states, and a parallel increase in social media usage created a perfect storm for increased toxicity of social media posts which this study sought to examine.

\section{Contribution of the study}

The aim of this study was to use sentiment analysis to examine the subjective nature and emotional toxicity of an organization's social media comments before and during COVID-19. This study utilizes Microsoft Azure Learning that is embedded within Microsoft Excel to analyze the comments. The goal of the research is to help businesses use social media data and sentiment analysis to help make better business decisions during the uncertainty of the COVID-19 pandemic and beyond. This process would also be able to be extrapolated to other areas and timeframes.

\section{Methodology}

This study evaluated the public Facebook page for a popular, national, Italian food chain restaurant (Olive Garden) The dataset that was selected for this study centered around a popular US holiday (Christmas). The dataset examined in the study consisted of two dates, December 24, 2019, and December 24, 2020. These dates served as representation of the before and during COVID-19 perspective. These specific days were selected as it centers around an important Christian holiday which occurs every year (Christmas). Schaffer (2020) explained that the best time for organizations to engage with their customers on social media is during the holidays. He states that social media posts around the holiday are the most valuable posts for organizations as they have an emotional appeal to customers. Furthermore, customers tend to take vacation time around the holiday times.

Moreover, the author's selected the Olive Garden's December $24^{\text {th }}$ Facebook posts because the exact same picture and similar content was posted by Olive Garden in 2019 and 2020. Finally, the 2019 and 2020 posts contained a large number of comments to conduct a sentiment analysis.

The process for analyzing the data is as follows. First, the data needs to be captured (sometimes referred to as scrubbed) from the website. To accomplish this task in Facebook it is first necessary to find the Facebook ID for the company. A Facebook ID is a numeric unique identifier which is connected to a Facebook profile, group or page and can't be changed. This study utilized the FindmyFBID website (Figure 6 https://findmyfbid.in ) to find the Facebook ID was found for the Olive Garden. An alternative website that one could use is comment picker (Figure $7 \mathrm{https}$ ://commentpicker.com/find-facebook-id.php ) 


\section{Issues in Information Systems}

Volume 22, Issue 1, pp. 200-214, 2021

Find $\mathbf{m} \boldsymbol{y}$ fb id Facebook Tools Twitter Tools Instagram Tools Youtube Tools Random Generators Redolit Tools Text Tools Other Tools Blog

\begin{tabular}{ll}
\hline & Find Your Facebook ID \\
& $\begin{array}{l}\text { To find your Facebook personal numeric ID for facebook graph API operations, fb:admins, social plugins } \\
\text { Enter your Facebook profile URL below: }\end{array}$ \\
$\begin{array}{l}\text { Master the } \\
\text { Markets } \\
\text { with AAll }\end{array}$ & Fittp: //www facebook.com/YourProfileName \\
\hline
\end{tabular}

Figure 4. Find My FB ID website

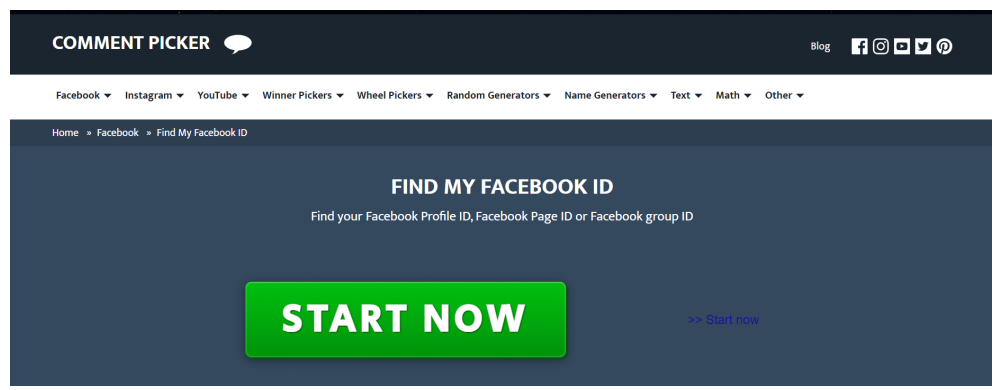

Figure 5. Comment Picker website

Second the content was fetched. This study used Facepager (Figure 8 https://github.com/strohne/Facepager) because it was a free application that is easy to download, install, and use (Peslak, 2018).

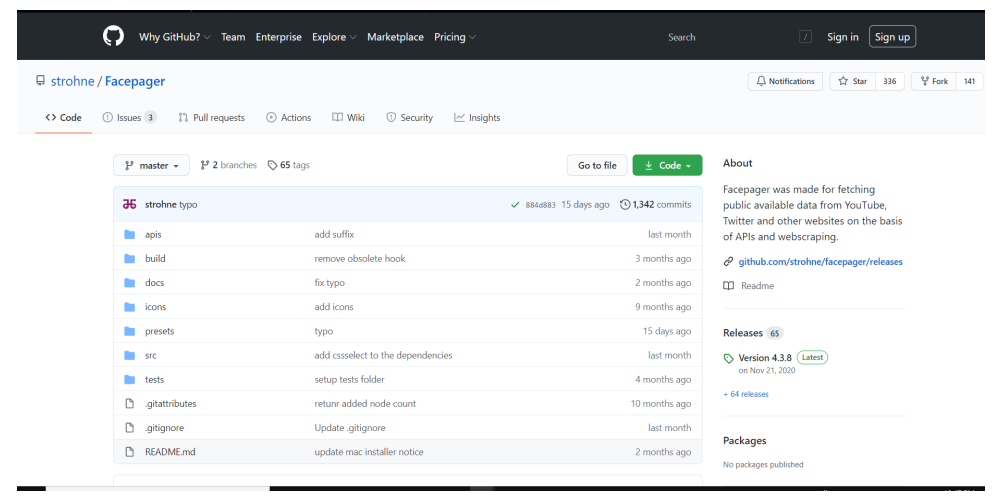

Figure 6. Facepager Website

Third, the data collected from Facepager was stored in a database file. This study used an SQLite database created by the authors. SQLite (Figure 9 https://sqlitestudio.pl/) was used because it is open source (free) and can be used on the MS Windows, Apple Mac, and Linux platforms. 


\section{Issues in Information Systems}

Volume 22, Issue 1, pp. 200-214, 2021

SQLiteStudio

Home News Gallery Download GitHub

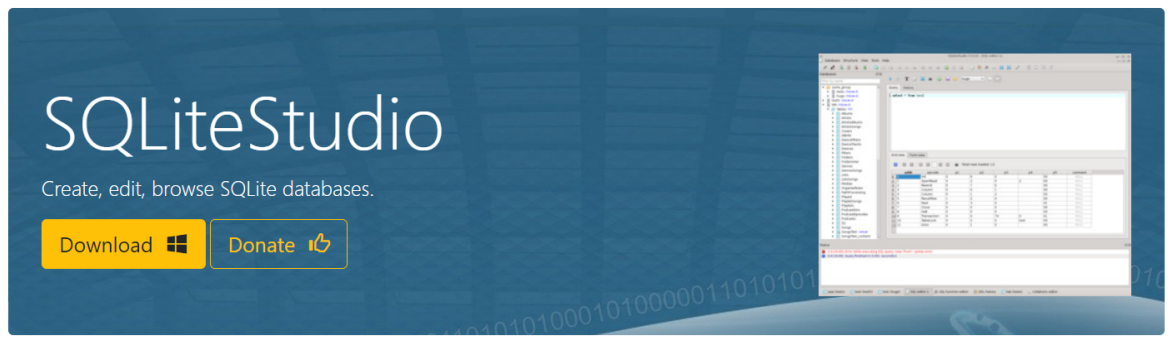

Figure 7. SQLite Studio

Fourth, the data was then exported to a common separated values (csv) file and then imported into Microsoft Excel. Fifth, the data preprocessing took place to remove any duplicates, blank posts, names of people, and replies from the Italian food chain restaurant. Once the data preprocessing was completed the data was analyzed for sentiment using the Microsoft Azure machine learning for sentiment analysis addin for Excel (Figure 10), Like the other software this add-in is easy to use, has great capabilities, and it included as part of the Microsoft Excel 365/19 package (Peslak, 2018).

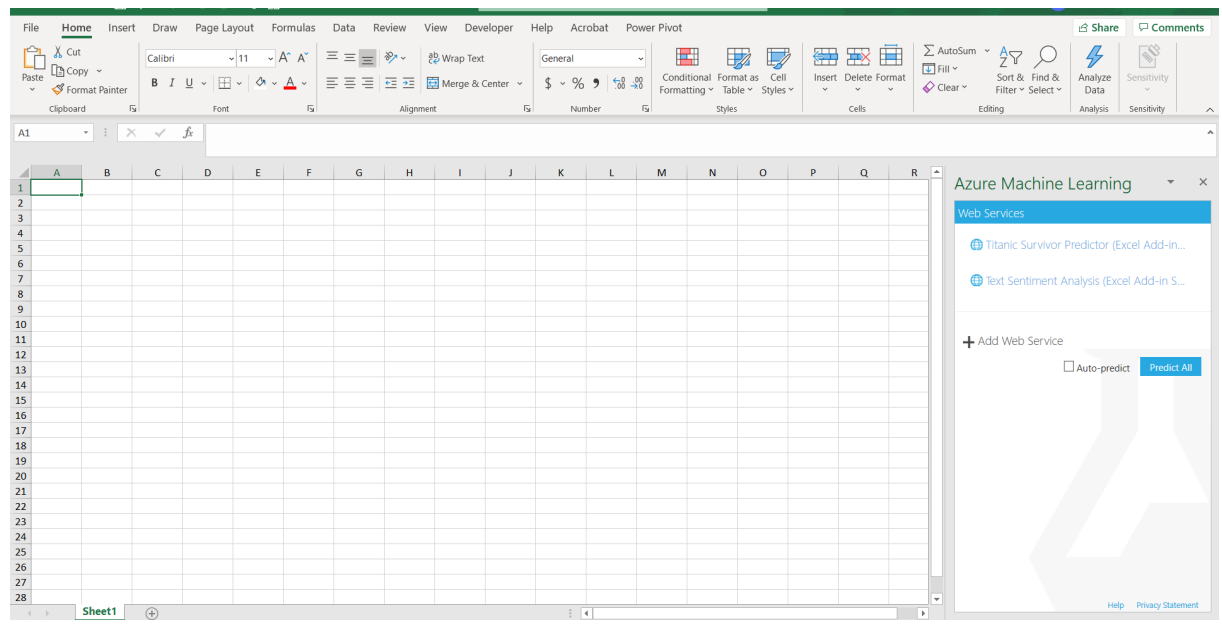

Figure 8. Microsoft Azure Machine Learning for Excel Add-In

\section{Results}

On January 28, 2021, there was a total of 6,189,319 followers on the Facebook page for the national Italian food chain restaurant. Over 200 comments originally fetched from Facepager for the two days. After preprocessing took place, there was a total of 69 comments in 2019 and 86 comments in 2020.

The comments were analyzed with three sentiment analysis categories created: positive, negative, and neutral. The sentiment scores closest to 1.00 indicate a strong positive valence/feeling. Similarly, sentiment scores closer to 0.00 indicate negative valence/feeling. Scores closer to the middle (0.50) were considered to indicate a neutral valence/feeling. An individual sentiment for the number of positive, neutral, negative scores for each comment in 2019 and 2020 for the December $24^{\text {th }}$ post is summarized in Table 1. The exact individual assessment scores are listed in the Appendix on Table 2. The overall sentiment score for the posts for 2019 was a positive 0.70 . Whereas the overall sentiment score for 2020 was neutral 0.57 . 


\section{Issues in Information Systems}

Volume 22, Issue 1, pp. 200-214, 2021

\begin{tabular}{|l|r|l|l|r|r|}
\hline \multicolumn{7}{|c|}{ Table 1: Sentiment Scores } \\
\hline \multicolumn{3}{|c|}{ 2019 Data } & \multicolumn{3}{c|}{ 2020 Data } \\
\hline Sentiment & Number & $\begin{array}{l}\text { Total } \\
\text { Percent }\end{array}$ & Sentiment & Number & $\begin{array}{l}\text { Total } \\
\text { Percent }\end{array}$ \\
\hline Positive & 51 & $74 \%$ & Positive & 51 & $59 \%$ \\
\hline Neutral & 9 & $13 \%$ & Neutral & 12 & $16 \%$ \\
\hline Negative & 9 & $13 \%$ & negative & 21 & $25 \%$ \\
\hline
\end{tabular}

These results indicate that there is a change in the sentiment of the post during COVID-19. While it is uncertain that the change resulted from the emotional challenges of COVID-19, it may be a contributing factor. Thus, the authors believe it is critical to recognize that COVID-19 challenges can impact social media data. Business can use sentiment analysis as a mechanism to help determine the emotional state of person posting the comment online. For example, the Olive Garden could use these results as indicator to offer more rewarding promotions that generate goodwill and good cheer. The business could make a point to increase its messaging strategy to help increase morale. Lastly, the Olive Garden could use the results to better monitor it performance and overall customer satisfaction.

\section{Limitations, future research, conclusion}

There are some limitations to this study that should be addressed. First, this research is limited in size as it only explored one organization's social media post. Second, the study only used two data points centered around a holiday. Third, even though the data was clean of sarcasm, this study did not evaluate sarcasm in the natural language processing process. Fourth, this research is assuming that organizations consider social media data when making business decisions. Finally, it is important to note that a comment to a post can be just an event's reaction by time, and not necessarily demonstrate one's emotional thought process. Thus, comments do not necessarily represent one's true and entire emotional state but, it can provide a starting point to understand a possible connection.

There are many ways future research can address these limitations. First, multiple restaurants could be explored as well as other industries. Also, more data points could be analyzed and perhaps adding dates that center around positive or negative COVID-19 news (i.e., vaccines versus new strains). Lastly, a sentiment analysis could be mapped toward before and after business decisions/announcements as tool to measure and make better business decisions.

The study sought to use sentiment analysis to examine the subjective nature and emotional toxicity of an organization's social media comments before and during COVID-19. This paper provides practical implications for higher education faculty teaching organizational decision making and analytics courses by presenting and documenting the process of using Microsoft Azure Machine Learning for sentiment analysis. This paper also has significant implications for practitioners considering or using social media data to drive business decision making. 


\section{Issues in Information Systems}

Volume 22, Issue 1, pp. 200-214, 2021

\section{References}

Alcohol.org (2021). Drinking Alcohol When Working from Home. American Addiction Centers, https://www.alcohol.org/guides/work-from-home-drinking/

Alexander, M. (2020, October 12). The emotional effects of grief after bereavement. http://knowyourgrief.org/grief-information/emotional-effects-of-grief/.

Bandeli, K. K., \& Agarwal, N. (2018). Analyzing the role of media orchestration in conducting disinformation campaigns on blogs.

Barnes, C. \& Wills, M. (2020). Social Media During the Time of COVID-19. https://www.psychologytoday.com/intl/blog/mental-illness-in-america/202012/social-mediaduring-the-time-covid-19

Bulman, M., 2020. "I'll go bonkers": How over-70's are reacting to coronavirus self-isolation, London: The Independent. https://www.independent.co.uk/news/uk/home-news/coronavirus-selfisolation-elderly-people-stay-at-home-uk-a9405411.html

Chodkiewicz, J., Talarowska, M., Miniszewska, J., Nawrocka, N., \& Bilinski, P. (2020). Alcohol consumption reported during the COVID-19 pandemic: the initial stage. International Journal of Environmental Research and Public Health, 17(13), 4677.

Dalli, K. (2021). Harmful alcohol use has increased during the COVID-19 pandemic. https://www.consumeraffairs.com/news/harmful-alcohol-use-has-increased-during-the-covid-19pandemic-021621.html

DeValck K. (2020). What is the Role of Social Media during the COVID-19 Crisis? https:/www.hec.edu/en/knowledge/instants/what-role-social-media-during-covid-19-crisis-0

Drinkaware. (2021). Alcohol and mental health. https://www.drinkaware.co.uk/facts/health-effects-ofalcohol/mental-health/alcohol-andmentalhealth\#: :text=And\%20regardless $\% 20$ of $\% 20$ the $\% 20$ mood, or $\% 20$ depressed $\% 20$ when $\% 20$ they\%20drink.

Drizly (2020) How alcohol ecommerce sales are being impacted across North America. https://drizly.com/article/e-1735e090

Furnari, C. (2020). Online Alcohol sales surg amid coronavirus pandemic. Forbes https:/www.forbes.com/sites/chrisfurnari/2020/12/01/online-alcohol-sales-surge-amidcoronavirus-pandemic/?sh=5b9e5e664f3a

Gates, B. (2020, March 20). Texans drinking the most alcohol during COVID-19 outbreak, data suggests. Kxan.com https://www.kxan.com/news/weird-news/texans-drinking-the-most-duringcovid-19-data-suggests/

Gostin, L. O., Hodge, J. G., \& Wiley, L. F. (2020). Presidential powers and response to COVID19. Jama, 323(16), 1547-1548. 


\section{Issues in Information Systems}

Volume 22, Issue 1, pp. 200-214, 2021

Jilani TN, Jamil RT, Siddiqui AH. H1N1 Influenza. [Updated 2020 Nov 30]. In: StatPearls [Internet]. Treasure Island (FL): StatPearls Publishing; 2021 Jan. https://www.ncbi.nlm.nih.gov/books/NBK513241/

Jones, X. R., \& Keynes, M. (2020). Covid-19: An Exposition, with a Focus on Social Isolation in the Elderly (UK). preprint.[Google Scholar].

Kantar (2021). COVID-19 Barometer: The leading syndicated study on how COVID-19 is influencing consumer behavior, attitudes and expectations, covering over 60 markets. https://www.kantar.com/campaigns/covid-19-barometer

Kantar (2020). COVID-19 Barometer: Consumer attitudes, media habits and expectation. https://www.kantar.com/inspiration/coronavirus/covid-19-barometer-consumer-attitudes-mediahabits-and-expectations

Kashif, M., \& Aziz-Ur-Rehman, M. K. J. (2020). Social media addiction due to coronavirus. International Journal of Medical Science in Clinical Research and Review, 3(04), 331-336.

Killgore, W. D., Cloonan, S. A., Taylor, E. C., Lucas, D. A., \& Dailey, N. S. (2020). Alcohol dependence during COVID-19 lockdowns. Psychiatry research, 113676.

Leetaru, K. (2018). Is social media becoming too toxic? Forbes.com. Retrieved April 1, 2021, from https://www.forbes.com/sites/kalevleetaru/2018/07/19/is-social-media-becoming-tootoxic/?sh=26349fa4f0c7

Majo-Vasquez, S., Nielson, R., Verdu, J., Rao, N., De Domenico, M., \& Papapiliopoulos, O. (2020). Volume and patterns of toxicity in social media conversations during the COVID-19 pandemic. Reuters. Retrieved April 1, 2021, from https://reutersinstitute.politics.ox.ac.uk/volume-andpatterns-toxicity-social-media-conversations-during-covid-19-pandemic

McKetta, S., Morrison, C. N., \& Keyes, K. M. (2020). Trends in US Alcohol Consumption Frequency During the First Wave of the SARS-CoV-2 Pandemic. Alcoholism: Clinical and Experimental Research.

Moon, S. (24 April 2020). A seemingly healthy woman's sudden death is now the first known US coronavirus-related fatality. https:/www.cnn.com/2020/04/23/us/california-woman-firstcoronavirus-death/index.html CNN.

Moukarzel, S., Del Fresno, M., Bode, L., \& Daly, A. J. (2020). Distance, diffusion and the role of social media in a time of COVID contagion. Maternal \& child nutrition, 16(4).

National Center for Immunization and Respiratory Diseases (NCIRD), Division of Viral Diseases (2020a). Social distancing.https://www.cdc.gov/coronavirus/2019-ncov/prevent-gettingsick/socialdistancing.html\#: :text=Social\%20distancing\%20should $\% 20 \mathrm{be} \% 20$ practiced,for $\% 20$ at $\% 20$ least $\% 2020 \% 20$ seconds. 


\section{Issues in Information Systems}

Volume 22, Issue 1, pp. 200-214, 2021

National Center for Immunization and Respiratory Diseases (NCIRD), Division of Viral Diseases (2020b). Grief and Loss.https://www.cdc.gov/coronavirus/2019-ncov/daily-life-coping/stresscoping/grief-loss.html

Neill, E., Meyer, D., Toh, W. L., Van Rheenen, T. E., Phillipou, A., Tan, E. J., \& Rossell, S. L. (2020). Alcohol use in Australia during the early days of the COVID-19 pandemic: initial results from the COLLATE project. Psychiatry and Clinical Neurosciences, 74(10), 542-549.

Novotney, A. (2019). The risks of social isolation. https://www.apa.org/monitor/2019/05/ce-cornerisolation

Peslak, A. (2018). Facebook Fanatics: A Linguistic and Sentiment Analysis of the Most "Fanned" Facebook Pages Journal of Information Systems Applied Research, 11(1), 23-33. http://jisar.org/2018-11/n1/JISARv11n1p23.html

Pietromarchi, V. (2020). Why is Italy's coronavirus fatality rate so high?, Qatar, Doha: AL Jazeera https://www.aljazeera.com/news/2020/3/24/why-is-italys-coronavirus-fatality-rate-so-high

Pollard, M. S., Tucker, J. S., \& Green, H. D. (2020). Changes in adult alcohol use and consequences during the COVID-19 pandemic in the US. JAMA network open, 3(9), e2022942-e2022942.

Ratini, M. (2020, August 06). Depression Overview: Emotional Symptoms, Physical Signs, and More. https://www.webmd.com/depression/ss/slideshow-depression-overview.

Rodriguez, L. M., Litt, D. M., \& Stewart, S. H. (2020). Drinking to cope with the pandemic: The unique associations of COVID-19-related perceived threat and psychological distress to drinking behaviors in American men and women. Addictive behaviors, 110, 106532.

Robinson, S. (2019). Isolation Has Profound Effects on The Human Body and Brain. Here's What Happens, s.1.: The Conversation, Science Alert.

Schaffer, N. (2020). 4 Reasons Why Holiday Posts are Crucial to Your Social Marketing Plan. https://nealschaffer.com/holiday-posts-social-media/

Shaw, N.,(2020). 1.4 million in UK will be told to cut all social contact from Monday, Cardiff, Wales: Wales Online.

Singer, C., (2018). Health Effects of Social Isolation and Loneliness. Journal of Aging Life Care, Issue Spring, p. NA.

Statista (2020, April 28) Reasons for increase in alcohol consumption related to COVID_19 in Canada. https://www.statista.com/statistics/1113300/reasons-for-increase-in-alcohol-consumptionsamong-canadians/

Szajnoga, D., Klimek-Tulwin, M., \& Piekut, A. (2020). COVID-19 lockdown leads to changes in alcohol consumption patterns. Results from the Polish national survey. Journal of Addictive Diseases, 112. 


\section{Issues in Information Systems}

Volume 22, Issue 1, pp. 200-214, 2021

Tennakoon, J. (2020). Machine Learning using Azure - Creating a Sentiment Analyzer. https://medium.com/99xtechnology/sentiment-analyzer-in-5-minutes-141077709c02

Wikipedia (2021). COVID-19 pandemic. https://en.wikipedia.org/wiki/COVID-19_pandemic

\section{Appendix}

\begin{tabular}{|l|r|l|l|r|}
\hline \multicolumn{5}{|c|}{ Table 2: Sentiment Scores } \\
\hline \multicolumn{2}{|c|}{ 2019 Data } & & \multicolumn{2}{c|}{ 2020 Data } \\
\hline Sentiment & Score & & Sentiment & Score \\
\hline positive & 0.86 & & positive & 0.98 \\
\hline positive & 0.74 & & positive & 0.94 \\
\hline negative & 0.44 & & positive & 0.64 \\
\hline negative & 0.17 & & neutral & 0.57 \\
\hline negative & 0.29 & & negative & 0.08 \\
\hline neutral & 0.48 & & negative & 0.18 \\
\hline positive & 0.74 & & negative & 0.09 \\
\hline negative & 0.17 & & positive & 0.64 \\
\hline positive & 0.85 & & positive & 0.62 \\
\hline neutral & 0.56 & & positive & 0.69 \\
\hline positive & 0.83 & & positive & 0.84 \\
\hline positive & 0.73 & & negative & 0.24 \\
\hline positive & 0.65 & & negative & 0.01 \\
\hline positive & 0.98 & & positive & 0.76 \\
\hline neutral & 0.57 & & negative & 0.16 \\
\hline positive & 0.68 & & negative & 0.35 \\
\hline positive & 0.69 & & negative & 0.04 \\
\hline positive & 0.99 & & positive & 0.93 \\
\hline positive & 0.91 & & neutral & 0.56 \\
\hline negative & 0.31 & & negative & 0.01 \\
\hline positive & 0.86 & & positive & 0.99 \\
\hline positive & 0.80 & & positive & 0.65 \\
\hline positive & 0.65 & & positive & 0.84 \\
\hline positive & 0.86 & & positive & 0.72 \\
\hline neutral & 0.46 & & negative & 0.23 \\
\hline positive & 0.91 & & neutral & 0.56 \\
\hline positive & 0.71 & & neutral & 0.60 \\
\hline positive & 0.69 & & negative & 0.16 \\
\hline positive & 0.72 & & negative & 0.01 \\
\hline positive & 0.85 & & negative & 0.13 \\
\hline positive & 0.78 & & negative & 0.35 \\
\hline positive & 0.66 & & negative & 0.02 \\
\hline positive & 0.66 & & positive & 0.98 \\
\hline negative & 0.41 & & negative & 0.42 \\
\hline
\end{tabular}




\section{Issues in Information Systems}

Volume 22, Issue 1, pp. 200-214, 2021

\begin{tabular}{|l|l|l|l|l|}
\hline positive & 0.74 & & positive & 0.85 \\
\hline positive & 0.66 & & positive & 0.64 \\
\hline negative & 0.29 & & positive & 0.72 \\
\hline negative & 0.07 & & positive & 0.78 \\
\hline negative & 0.31 & & positive & 0.76 \\
\hline positive & 0.84 & & positive & 0.69 \\
\hline neutral & 0.59 & & negative & 0.28 \\
\hline negative & 0.17 & & negative & 0.29 \\
\hline positive & 0.65 & & positive & 0.89 \\
\hline positive & 0.71 & & positive & 0.86 \\
\hline positive & 0.70 & & positive & 0.76 \\
\hline neutral & 0.58 & & positive & 0.70 \\
\hline positive & 0.82 & & positive & 0.63 \\
\hline positive & 0.76 & & negative & 0.01 \\
\hline positive & 0.74 & & negative & 0.24 \\
\hline positive & 0.82 & & positive & 0.64 \\
\hline neutral & 0.59 & & positive & 0.80 \\
\hline neutral & 0.55 & & positive & 0.74 \\
\hline positive & 0.67 & & positive & 0.69 \\
\hline positive & 0.98 & & positive & 0.73 \\
\hline positive & 0.75 & & neutral & 0.52 \\
\hline positive & 0.66 & & neutral & 0.48 \\
\hline positive & 0.67 & & neutral & 0.51 \\
\hline positive & 0.79 & & positive & 0.82 \\
\hline positive & 0.69 & & positive & 0.66 \\
\hline positive & 0.89 & & positive & 0.61 \\
\hline positive & 0.71 & & neutral & 0.52 \\
\hline positive & 0.66 & & positive & 0.69 \\
\hline neutral & 0.48 & & neutral & 0.54 \\
\hline negative & 0.36 & & positive & 0.66 \\
\hline neutral & 0.49 & & positive & 0.66 \\
\hline positive & 0.77 & & positive & 0.73 \\
\hline positive & 0.66 & & positive & 0.91 \\
\hline negative & 0.40 & & positive & 0.70 \\
\hline positive & 0.69 & & positive & 0.90 \\
\hline positive & 0.73 & & positive & 0.68 \\
\hline positive & 0.91 & & positive & 0.66 \\
\hline positive & 0.66 & & positive & 0.76 \\
\hline positive & 0.66 & & neutral & 0.50 \\
\hline positive & 0.66 & & positive & 0.60 \\
\hline & & & positive & 0.71 \\
\hline & & & positive & 0.69 \\
\hline & & & nositive & 0.74 \\
\hline & & & 0.53 \\
\hline
\end{tabular}




\section{Issues in Information Systems}

Volume 22, Issue 1, pp. 200-214, 2021

\begin{tabular}{|l|l|l|l|r|}
\hline & & & negative & 0.41 \\
\hline & & & positive & 0.72 \\
\hline & & & positive & 0.71 \\
\hline & & & positive & 0.66 \\
\hline & & & positive & 0.66 \\
\hline & & & positive & 0.66 \\
\hline & & & negative & 0.44 \\
\hline
\end{tabular}

